See Article page 2057 .

\section{Commentary: When there is a will, there is a way}

\author{
Waël C. Hanna, MDCM, MBA, FRCSC
}

Informative pretreatment tissue diagnosis has become an essential component of the continuum of lung cancer care. Often times, when tissue is not accessible, we find ourselves making decisions to treat patients based on the best-available information, otherwise known as speculation. In this issue of the Journal, Molina and colleagues $^{1}$ challenge, and break down, one of the last remaining barriers to tissue diagnosis, namely, when the target is hiding behind a big scary blood vessel.

Passing a needle through and through both walls of the aorta or the pulmonary artery to obtain a tissue sample from the other side may sound like blasphemy, but the argument is actually compelling. It is not rare that vessels are inadvertently punctured (despite all precautions) during a routine endobronchial ultrasound/endoscopic ultrasound procedure. Considering that thousands of procedures are done each year, the fact that catastrophic hemorrhage is rarely reported supports the hypothesis that it is probably safe to puncture a vessel with a small $22-\mathrm{G}$ needle and get away with it. In this series, the authors present 100 such cases and report only 1 delayed vascular complication, a pseudoaneurysm of the aorta. It was determined that the sensitivity, specificity, and accuracy of the procedure were all greater than $70 \%$, and the diagnostic yield was $80 \%$, all figures that compare well with other more-invasive biopsy techniques, such as transthoracic needle biopsy.

The patients in this series were very carefully selected, as should be the case when a high-risk technique is being planned. It is assumed that patients with ominous vascular features (calcification, atherosclerosis, aneurysm) were not biopsied, but it is not explicitly stated what proportion of planned transvascular biopsies were aborted because of

\footnotetext{
From the Division of Thoracic Surgery, McMaster University, Hamilton, Ontario, Canada.

Disclosures: Author has nothing to disclose with regard to commercial support.

Received for publication Nov 25, 2019; accepted for publication Nov 26, 2019; available ahead of print Jan 24, 2020.

Address for reprints: Waël C. Hanna, MDCM, MBA, FRCSC, St Joseph's Healthcare Hamilton, 50 Charlton Ave E, Juravinski Tower, Suite T2105 F, Hamilton, Ontario L8N4A6, Canada (E-mail: hannaw@mcmaster.ca).

J Thorac Cardiovasc Surg 2020;159:2068

0022-5223/\$36.00

Copyright (c) 2019 by The American Association for Thoracic Surgery

https://doi.org/10.1016/j.jtcvs.2019.11.076
}

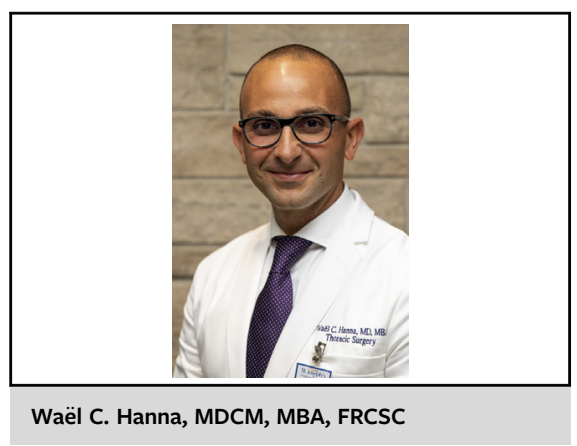

CENTRAL MESSAGE

In the era of highly specific personalized and molecular

medicine, we have almost no excuse for not obtaining tissue diagnosis when it is necessary.

such features. A closer look at the data reveals that $42 \%$ of patients who underwent transvascular sampling ultimately had benign targets. This raises the question whether more diligent use of preoperative staging with imaging and endosonographic criteria could've avoided those biopsies. Another lingering question, which is inherent to the retrospective nature of the data, is whether those benign diagnoses changed patient management in any appreciable way. However, what is reported in this paper is nothing short of a game changer-what was thought to be unsafe and low yield turns out to be safe and high yield.

When there is a will, there is a way. In the era of highly specific personalized and molecular medicine, we have almost no excuse for not obtaining tissue diagnosis when it is necessary. This paper is a strong argument for why we need to master endobronchial ultrasound/endoscopic ultrasound techniques and why we should continuously question the boundaries of what is possible in a thoracic surgeon's hands.

\footnotetext{
Reference

1. Molina JC, Chaudry F, Menezes V, Ferraro P, Lafontaine E, Martin J, et al. Transvascular endosonographic-guided needle biopsy of intrathoracic lesions. J Thorac Cardiovasc Surg. 2020;159:2057-65.
} 